\title{
Preocupaciones y desafíos de la política en tres ciudades de frontera: Puerto Iguazú, Foz do Iguaçu y Ciudad del Este ${ }^{1}$
}

\author{
FERNANDA MAIDANA
}

¿Cómo abordar 'la política ${ }^{2}$ en Puerto Iguazú, Foz do Iguaçu y Ciudad del Este?, ciudades de frontera que pertenecen a tres países limítrofes, que muestran peculiaridades dadas por su posición geopolítica y por ciertas características específicas y que, a diferencia de municipios no fronterizos, sus dirigentes deben vincularse mucho más con los gobiernos centrales. En primer lugar, este interrogante supone pensar más allá de definiciones normativas y conceptualizaciones arbitrarias y, en tanto categoría etnográfica, preguntarnos sobre 'la política que es hecha, la que las personas dicen hacer o identifican como siendo hecha por los otros' (Palmeira, M. y C. Barreira 2006). ${ }^{3}$ Esto es, cómo comprenden y experimentan las propias personas del universo estudiado aquello que es entendido como política. No debemos olvidar que en sociedades como las nuestras se presenta asociada a un entramado de instituciones especializadas y constituyendo un dominio separado, a contramano de lo que muchas veces podemos encontrar: las actividades tenidas como políticas se entrecruzan e interpenetran con aquello considerado económico, jurídico, religioso, etc. La investigación empírica puede revelar éstas y otras singularidades de sentidos, objetos y prácticas asociados.

\footnotetext{
1 Este trabajo es parte de mi investigación de posdoctorado sobre prácticas políticas en ciudades de frontera, aquí presento un primer avance. Agradezco las sugerencias y comentarios generosos de Andrea Ciacchi, Silvia Montenegro y Lindomar Albuquerque.

2 De aquí en adelante uso las itálicas para expresiones de las personas, de relatos y de crónicas, y las comillas simples para términos propios, categorías analíticas, citas de autores y para relativizar algunas expresiones. La traducción del portugués al castellano es mía, y cuando refiero a las denominaciones brasileñas de vereadores y prefeitos deben entenderse como equivalentes a las de concejales e intendentes de los sistemas políticos argentinos y paraguayos.

3 Estoy considerando aquí el abordaje propuesto por el Núcleo de Antropologia da Política (Nuap) que articuló investigadores de diferentes universidades brasileñas en los años 1997 - 2005 en torno al proyecto "Uma antropologia da política: rituais, representações e violencia”, cuya prolífica producción compone treinta y dos libros - considerando la Coleção Antropologia da Politica que reúne sólo una parte de sus resultados- (Comerford y Bezerra 2013), e influenció de forma marcada líneas de investigación desarrolladas por antropólogos en Argentina (Frederic y Soprano 2008).
} 
En segundo lugar, observar las modalidades que adquiere en las tres ciudades supone considerar con Fortes y Evans-Pritchard que 'el punto en el cual terminan las relaciones políticas, definidas superficialmente en términos de acción militar y sanciones legales, no es el mismo en que cesan todas las relaciones sociales' (Fortes y Evans-Pritchard 2010: 89). Aún mejor que otros contextos empíricos podemos ver cómo las poblaciones de estas ciudades divididas por límites político - administrativos que responden a procesos históricos, políticos e identitarios específicos, correspondientes a tres países (Argentina, Brasil y Paraguay), dos de ellos colindantes (Foz y a Ciudad del Este), se vinculan y dependen entre sí por diversos y variados motivos tal como ha sido señalado por numerosos investigadores. ${ }^{4}$ No obstante, los entramados, códigos compartidos y configuraciones resultantes, así como las dinámicas translocales, se asientan en la existencia de fronteras nacionales ${ }^{5}$ (Rabossi 2003; Cardin 2009; Albuquerque 2008) y no en su elusión, y son posibles por todo lo que éstas suponen en tanto diferentes sistemas jurídicos, económicos, etc. Las personas de estos contextos empíricos participan de tales entramados, configuraciones y códigos y, en ello, muestran formas específicas y coyunturales de vincularse con los sistemas jurídico-legales de estos países. ${ }^{6}$ Por esto, debemos considerar que más allá de la importante población migrante y flotante, sus pobladores pueden no manifestar una relación unívoca entre ejercicio de ciudadanía, identidad nacional y residencia.

En la dirección de pensar la naturaleza jurídico-administrativa de los Estados-Nación, ésta circunscribe las estructuras, funciones y competencias político-administrativas a jurisdicciones y espacios específicos de la que no escapan las zonas fronterizas que, además, como señalaron algunos investigadores $^{7}$, resultan de interés y particular intervención de los gobiernos centrales de los países respectivos. Más que proponer la oposición entre lo local y lo nacional, o la subordinación de la primera a la segunda, o incluso su abordaje como esferas autónomas, considero con Bezerra (2006) que estas perspectivas imponen límites al entendimiento y que, en cambio, atender a las articulaciones existentes entre políticos en ellas situadas permite comprender lo que la política moviliza tanto en los municipios como en el ámbito nacional. En este trabajo propongo que los entendimientos y prácticas de los dirigentes de estas ciudades muestran formas diversas de relacionar espacios sociales de escala diferente. ${ }^{8}$

Inicialmente me llamaba la atención cómo 'la política' ganaba densidad cuando se hacían presentes diferentes universos políticos y escalas de actuación y se expresaban dimensiones translocales y

4 Ver, por ejemplo, Rabossi (2003), Machado (2009), Albuquerque (2008), Montenegro y Giménez Béliveau (2010) y Renoldi (2013).

5 Esto lo podemos encontrar muy claramente expresado en Rabossi (2003) cuando señala que, aunque las múltiples relaciones comerciales entre Ciudad del Este y Foz do Iguaçu pueden hacernos pensar en un espacio urbano continuo en el que el límite internacional sería una abstracción, es justamente por la existencia de ese límite y sus regímenes legales diferenciados que son posibles estos vínculos.

6 Como en el caso de madres paraguayas que utilizan el sistema público de salud argentino para los nacimientos y el acceso de sus hijos a programas materno - infantiles u otros beneficios de la salud pública o sociales argentinos; aunque considerado fortuito y al efecto de preservar la salud en el momento del parto, el caso de mujeres de Puerto Iguazú de sectores medios que buscando servicios especializados como el de neonatología, del que carece esta ciudad, recurren a clínicas privadas de Foz do Iguaçu y sus hijos acaban con doble nacionalidad; y el caso tan bien estudiado por Albuquerque (2012) de los brasiguayos que viven en Paraguay y accionan derechos y beneficios sociales en el lado brasilero.

7 Ver, por ejemplo, Grimson (2005) y Giménez Béliveau (2011).

8 Bezerra $(1999,2006)$ analiza la actuación de parlamentarios en el Congreso Nacional brasilero y la importancia que ocupan las relaciones con autoridades gubernamentales y políticos locales observando los distintos planos de acción política. Sobre Foz do Iguaçu y Ciudad del Este, Giménez Béliveau (2011) señaló que los políticos de estas ciudades perciben que la posibilidad de resolver sus problemas y toma de decisiones pasa por distintas escalas en que se manejan las decisiones políticas. 
transnacionales. La destitución del presidente paraguayo Lugo en 2012 producía un encadenamiento vertiginoso de sucesos que involucraba a élites políticas y sectores económicos, países próximos y distantes, acuerdos regionales y políticas internacionales que alcanzaban la dinámica turística y comercial local: disminuía el movimiento y el tránsito que articulaba a las tres ciudades y al cabo de unos días se militarizaba la zona. ${ }^{9}$ La acción política escapaba los límites del espacio nacional y sus ramificaciones se localizaban en estas ciudades. Del mismo modo, era posible observar en distintos momentos asuntos o problemas translocales como los recursos naturales y energéticos, el comercio fronterizo o el contrabando siendo temas de agendas nacionales que adquirían dimensiones transnacionales. Me preocupaba la búsqueda de los dirigentes de superar los límites de la experiencia política local - de sobreponerse a la falta de poder jurisdiccional sobre la frontera -, que involucraba de forma principal la articulación de espacios de escalas diferentes. Asimismo, veía que la creación de lazos políticos también otorgaba singularidad, la población migrante y flotante en las tres ciudades contribuía a la localización de diversos universos políticos y de desafíos al momento de construir nuevas lealtades políticas.

Buscando identificar qué necesitamos tener en cuenta para comprender 'la política que hacen' los dirigentes locales de Puerto Iguazú, Foz do Iguaçu y Ciudad del Este, me voy a detener particularmente en las preocupaciones o grandes temas sobre la ciudad tal como son entendidos por ellos mismos, y en cómo articulan sus reclamos en los otros niveles de actuación política mayormente desde la dimensión pública de esas relaciones. Aunque describo sus particularidades, por razones de espacio la descripción que presento no se detiene en las asimetrías entre estas ciudades (de sus estructuras de gobierno, recursos financieros municipales, etc.) ni tampoco en las relaciones entre los gobiernos centrales, las dinámicas político-partidarias internas y sus electorados.

Los debates de sesiones y audiencias públicas de los concejales y vereadores, así como el seguimiento de la prensa digital, en tanto foro de expresión de diferentes registros, narrativas, múltiples voces y posiciones que comprenden a la dirigencia local, mostraban ser una vía promisoria. Por esto, decidí seguir los intereses de la investigación a partir de su observación como discusiones, esto es, como modos públicos de describir, configurar y relatar la acción y momentos donde las personas realizan operaciones críticas, mientras denuncian, acusan, disputan y justifican (Boltanski y Thévenot 1991). Observar además los desacuerdos permite, atendiendo a Latour y su propuesta de abordaje de controversias, alcanzar diferentes marcos de referencia y huir de un punto de vista absoluto y arbitrario (Venturini 2010; Latour 2008).

Realicé el relevamiento de diarios de sesiones y de noticias de la prensa, la observación de sesiones y de eventos, y las entrevistas durante fines de 2014 y parte de 2015. Dado que no fue excluyente y que extendí el relevamiento de diarios de sesiones y noticias a 2007, pude constatar que los problemas enunciados por los dirigentes locales de las tres ciudades eran similares ${ }^{10}$; es decir, se expresaban las

\footnotetext{
9 Brasil enviaba nueve mil soldados a la frontera al conocerse que tropas paraguayas participaban de un entrenamiento militar en Panamá invitados por Estados Unidos (“Aliança militar entre EUA y Paraguai aumenta tensão”, 10 de agosto de 2012, www.brasil.47.com).

10 Elegí introducir profundidad temporal al relevamiento buscando superar la falta de registro documental en Puerto Iguazú. En 2007 se inicia la documentación y el archivo de las actas de sesiones del Consejo Deliberante de esta ciudad, como una iniciativa personal de algunas trabajadoras que veían necesario mejorar esos aspectos de la acción institucional. Este conjunto documental comprende uno de los pocos registros que se encuentran en la ciudad.
} 
mismas preocupaciones y discusiones en 2007 y en 2014. En Puerto Iguazú, la expansión de la ciudad ante una urbanización limitada, precaria y excluyente y el crecimiento del turismo; en Foz do Iguaçu el desarrollo y los obstáculos para alcanzarlo desde la falta de concreción de ciertas obras de infraestructura para la logística y el turismo; y en Ciudad del Este la crisis del comercio como forma de pensar y transformar la ciudad. Que las mismas preocupaciones fueran tematizadas en 2007 y en 2014 me parecía que afirmaba su carácter de grandes temas o problemas y significado cardinal para esos dirigentes; por otro lado, esa recurrencia que indica que tales preocupaciones tienen por lo menos algunos años de antigüedad podría responder a sentidos y coyunturas específicas de procesos más amplios que hacen al devenir de estas ciudades.

De esta forma abordo las preocupaciones de intendentes, concejales, vereadores y funcionarios, consideradas en grandes temas o problemas y que componen por su vez, discusiones sobre la ciudad. Siguiendo estos temas o problemas, al analizar cómo son definidos y las iniciativas al respecto de éstos, observo entendimientos y prácticas sobre el 'hacer política, como aquel hacer que es propio a los políticos (Palmeira y Barreira 2006). Buscando también reconocer en esas iniciativas formas específicas de relacionar espacios sociales de escala diferente.

\section{Puerto Iguazú: la expansión y el crecimiento}

Cuando comenzaba a conversar con funcionarios y dirigentes locales y a seguir sus actividades, me era presentada una imagen de Puerto Iguazú de crecimiento inédito espectacular del turismo y de eventos que le daban cierto brillo y esplendor. Sin embargo, la presencia de dirigentes locales en eventos 'chic', como la inauguración de un sofisticado hotel de alta categoría, la elegante Feria Artesanal del Mercosur, el Festival de Cine con visita de actores de primera plana nacional en los que nunca faltaba la presencia del gobernador y/o del Ministro de Turismo Provincial, se contrastaba con los problemas diarios en los que era posible observar a concejales y funcionarios municipales, vinculados a la expansión de la ciudad. Ellos lidiaban todo el tiempo con muchos barrios de la ciudad sin agua, sin luz y otras carencias que no conseguían resolver. Las actividades de estos dirigentes expresaban fuertes contrastes: de la precariedad de los barrios y la urbanización a la suntuosidad de los grandes hoteles y eventos turísticos, algunos fuera del país y del continente. Esas imágenes parecían ser las postales en que se expresaba Iguazú como objeto de la política y como dos focos de atención que producían tensiones: el turismo y los barrios.

A los pocos días de llegar a Iguazú, conversando con un trabajador él me recomendaba conocer lo que es Puerto Iguazú saliendo del centro, derecho por la [calle] República Argentina, y me anticipaba: vas a ver que allá hay una ciudad, otra ciudad, no es lo que vos ves aqui. Esta calle conducía a una gran área por donde la ciudad se expandía, invisible para los turistas al estar fuera y distante del circuito turístico local: la otra cara de la maravilla del mundo como gustaban decir algunos cronistas de los medios digitales ${ }^{11}$ y muchos pobladores (el otro Iguazú), mostraba una urbanización precaria en la que fal-

11 Puerto Iguazú no tiene medios de prensa gráfica; en cambio ofrece cuatro sitios digitales de publicación regular de noticias: iguazunoticias.com; www.lavozdecataratas.com; www.cvinoticias.com; www.radiocataratas.com. 
taba infraestructura básica. Esta cartografía era vivida como la de dos Puerto Iguazú: a) uno de ellos, el visible y citadino, reducido a unas pocas cuadras céntricas que, aunque próximo al standard de pequeña urbanización contemporánea, sufría de frecuentes cortes de luz (de hasta cinco o más algunos días), de agua corriente no potable, y de caídas de las líneas de comunicación (de telefonía fija y de celular) y de internet que dejaban incomunicada la ciudad por días enteros, parado su sistema bancario e inviable las transacciones comerciales a través de terminales electrónicas; b) el otro Puerto Iguazú, el que padece el morador al alejarse de las calles céntricas, sin desagües cloacales, pluviales ni pavimento o trazado de calles, con servicio eléctrico costoso cuando no inaccesible, precario y peligroso, sin tendido de red de agua y alumbrado público, y con recolección de basura deficiente o sin él. Dadas las constantes lluvias en las cuatro estaciones, muchas veces intransitable por el barro, y difícil para el desplazamiento.

En mis observaciones, en la prensa digital, en los diarios de sesiones, en las entrevistas y en las conversaciones que surgían de mi tránsito por la ciudad, era claro este contraste señalado por los pobladores y marcado en la acción política, que el esplendor de las Cataratas y el protagonismo económico convivían con imágenes y padecimientos contundentes de la urbanización restringida y excluyente de la ciudad.

\section{El turismo y la intensificación de su crecimiento}

A raíz de la devaluación económica de la moneda iniciada en 2002, que acaba siendo una ventaja competitiva para atraer al turismo internacional, en poco más de diez años se producía un crecimiento del $86 \%$ en visitas de turistas extranjeros al país, según datos oficiales que el Ministro de Turismo de la Nación refería en 2014. En pocos años el turismo se afirmaba en veloz crecimiento con la novedad y el empuje de convertirse la ciudad - en conjunto con Foz do Iguaçu - en un destino internacional consagrado, al haber sido elegidas en 2011 las Cataratas como una de las Siete Maravillas Naturales. El coordinador de la campaña argentina Vote Cataratas en una entrevista me decía: Entendiamos que estaba muy lindo el logro pero que era una oportunidad histórica para promover el desarrollo turístico de estas ciudades. Asimismo, en este proceso de expansión turística las Cataratas se posicionaban como el segundo destino de mayor atractivo ${ }^{12}$ de la Argentina, y como tal Iguazú tenía un protagonismo especial en las políticas de la cartera nacional.

Al pasar a ser un destino compitiendo con otros internacionales, desde la provincia se habia tomado la decisión politica de ser pro actividad turística, según me explicaba también el Secretario del Ente municipal de Turismo (Iturem); Iguazú ahora era objeto de una forma de desarrollo, de mucha inversión privada y por eso, de una mayor mirada, tal como me decía otro funcionario, considerando al sector privado del Turismo como generador de ingresos y, desde el municipio, las politicas de turismo como líneas que venían de la provincia y de la Nación. Esta actividad presentaba nuevas perspectivas para la economía de la provincia, incluso, se convertía en una de las principales, la tercera en relevancia siguiendo a la yerba mate y a la madera. Si bien Iguazú recibía en 2013 un millón trescientos mil turistas en Cataratas,

12 Era capaz de competir como uno de los destinos más buscados de Argentina, el segundo en 2014 y 2015 según Trivago (metabuscador mundial de hoteles, viajes y ciudades). 
sumaban muchos más en toda la provincia. El cambio de dirección en las agendas nacional, provincial y municipal se expresaba no sólo en que Iguazú pasaba a contar en poco más de diez años con quince mil camas, sino en las preocupaciones de los dirigentes y en nuevas discusiones.

Las políticas provinciales de apoyo al turismo - tributarias, de infraestructura y promoción con foco en Iguazú parecían destinarse fundamentalmente al apoyo a la inversión privada y a emprendimientos foráneos, vistos como promotores de turismo competitivo y generadores de crecimiento económico y de empleo. Éstas eran defendidas en la teoría del derrame (la economía por sí misma generaría beneficios para todos) y en el entendimiento, por entonces, de que el sector era el que más puestos de trabajo creaba, considerando que la provincia en los últimos siete años había tenido un 140\% de aumento en establecimientos y plazas - camas (en Puerto Iguazú éste era del 172\%), según era declarado en la Feria Internacional de Turismo en 2015. Pude observar que la orientación de esos emprendimientos privados, tal como refería el gobernador, era sobre todo hacia la construcción e instalación de hoteles - en siete años quince hoteles sustentables en la zona denominada las 600 hectáreas - y aún no contemplaba, por ejemplo, el emplazamiento de sitios de entretenimientos como parques de diversiones, grandes centros comerciales o cines, de los que llamativamente carecía la ciudad.

Aunque Iguazú se había reconvertido del comercio al turismo y sus pobladores pasaban a vivir de esta actividad en los últimos diez años como gastronómicos, hoteleros, etc, era posible observar en diversas ocasiones declaraciones e iniciativas de las autoridades locales y provinciales que destacaban que la población local (y sus emprendimientos económicos) ofrecía servicios no siempre competitivos para atraer el turismo, sobre todo, el de alta categoría. Aludían a la baja calidad de los alojamientos, su sobreoferta y falta de regulación, las formas 'incompetentes' con que trataban al turista - por desconocer idiomas, información, etc -, y otras características como el caso de terrenos de Parques Nacionales en el centro de la ciudad, considerado por el Intendente como 'fuente de atraso'.

No obstante, concejales de la oposición y algunos cronistas denunciaban insistentemente que los grandes emprendimientos instalados, como un casino y el shopping libre de impuestos de la zona franca, tenían ganancias millonarias que no redundaban en beneficios para la ciudad (la redistribución es nula), excepto por los trabajos que generaban para sus habitantes. No somos muy diferentes a Wanda o a Esperanza [pequeñas localidades vecinas], Esperanza tiene una plaza mejor que la nuestra, me decía un comerciante con cierto malestar. La plaza en tanto cara de presentación, como es considerada en muchas ciudades argentinas, no mostraba proporción con el crecimiento de esos emprendimientos económicos. Para el gobernador, el intendente y el Ministro de Turismo - tres figuras cuyo perfil de empresarios del turismo no pasaba desapercibido -, los nuevos y grandes emprendimientos eran los generadores del progreso de Iguazú, en tanto que para muchos pobladores comprendían flujos de dinero que beneficiaban a unos pocos, y a gente que además no era de Iguazú. Asimismo, era entendido que esas politicas no consideraban a la ciudad en su conjunto ni a otros sectores. Una concejal opositora en una entrevista que le hago resaltaba con cierta indignación que se está dejando de lado la planificación de la ciudad y, en la misma dirección, un concejal opositor indicaba que esta orientación daba cuenta de por quécrecía tanto un sector y el otro no (sesión del 5 de diciembre de 2013), a propósito del comercio y de la falta de un planeamiento estratégico que contemplara la comunidad local en su integralidad. 
En 2002 se le había permitido a la empresa concesionaria de la Zona Franca (administradora de aeropuertos, puertos y zonas francas del país), emplazar el shopping libre de impuestos en el área primaria aduanera. Para algunos pobladores, por el vínculo personal de amistad del entonces gobernador de la provincia con el presidente del grupo económico que gestionaba este shopping. La localización prescindía de la burocracia fronteriza facilitando el ingreso del visitante al shopping y no así a la ciudad. Los comerciantes acusaban esto como una injusticia puesto que ellos padecían la burocracia de los controles migratorios, pagaban impuestos y recibían constantes controles de los organismos estatales. Un concejal de la oposición expresaba que existía un privilegio otorgado que, en lugar de favorecer el desarrollo económico de esta comunidad, de una manera absolutamente contraria, lo está perjudicando (sesión del 15 de marzo de 2007). De acuerdo a un blog de dirigentes opositores creado para la campaña electoral en 2015, mientras mil seiscientos comercios (sin contar con establecimientos gastronómicos y hoteleros) aportaban al municipio en concepto de Tasa Municipal más de dos millones y medio de pesos - y empleaban seis mil trabajadores -, el shopping libre de impuestos aportaba solamente doscientos mil. Los casinos de la ciudad también eran mencionados por la falta de control sobre sus actividades.

Del mismo modo, los comerciantes se sentían ignorados en sus reclamos sobre la dificultad que representaba la barrera migratoria; el trámite en el organismo argentino de migraciones muchas veces suponía largas esperas para entrar a la ciudad y el brasilero, considerado el consumidor por excelencia del comercio y la gastronomía local ${ }^{13}$, se volvía y recomendaba no visitarla. Tal como me explicaba un ex trabajador de Migraciones, se trataba de un sistema de aeropuerto, para el que pasa una vez cada tanto (no sirve para nosotros, me decía). Ésta comprendía una demanda que llevaban trece años de reclamos y gestiones ante el organismo nacional para la agilización del paso; con autoridades nacionales que no entendian, no se daban cuenta de cuáles son los problemas (en palabras de un concejal del oficialismo). Las casillas de controles prometidas con recursos de empresas privadas locales no se concretaban en su totalidad y, por si fuera poco, las autoridades provinciales gestionaban ante el gobierno central (para lo cual viajaba a Buenos Aires un Secretario Provincial) la apertura de un ingreso lateral, del lado izquierdo en el área conocida como las 600 hectáreas, y de un acceso a emprendimientos gastronómicos y hoteleros que también, como el shopping libre de impuestos, evitaría a los turistas extranjeros el trámite migratorio, el ingreso al pueblo y el correspondiente consumo en los comercios del pueblo.

El turismo considerado único agente de desarrollo económico, como política pública basada en el protagonismo de esta ciudad como destino turístico nacional y en su preponderancia económica para la provincia, se reflejaba también en que el Ministro de Turismo de la Nación la visitara con alguna frecuencia y en que el Gobernador y el Ministro de Turismo fueran figuras con presencia física semanal, como podía desprenderse de las crónicas de los medios de prensa , y con quienes el intendente (pariente del gobernador, su cuñado) interactuaba de forma permanente y personalizada, siguiendo las definiciones y medidas que estas figuras delineaban para la ciudad. En estas interacciones, podía observar distintas situaciones de gestiones ante organismos nacionales, coordinación de políticas y con-

13 Los compradores paraguayos también eran considerados consumidores de alimentos y productos de limpieza en supermercados mayoristas así como de materiales de construcción, no obstante, éste consumo parecía beneficiar a pocos comerciantes locales, no representar una fuente significativa de empleos y ser mayormente informal. Por otra parte, era posible ver que estas ventas disminuían de forma muy marcada con cada caída de ventas en el comercio de Ciudad del Este, mostrando la dependencia con la economía de esa ciudad. 
secución de beneficios de programas nacionales, donde mayormente las figuras provinciales eran los interlocutores en vínculos institucionales ante las autoridades nacionales y no así los dirigentes locales.

Aunque las autoridades municipales atendían diversas necesidades, como la construcción de una planta potabilizadora, el trazado, asfalto y empedrado de algunas calles, la colocación de semáforos, las iluminación de cuadras céntricas y las veredas, entre otros, incluso con el aporte de recursos provinciales, las políticas de la intendencia y de la gobernación recibían frecuentes comentarios negativos de los pobladores y eran resistidas y denunciadas de atender a los intereses económicos privados del grupo de poder.

En este sentido me decía un periodista mientras era construida una obra realizada por la provincia como atractivo turístico: ahora están pensando en poner un faro que cuesta millones, que larga luces y demás, y agregaba otras prioridades como agua, luz, educación, nada. Todo para el quincho de uno, aludiendo a que el nuevo atractivo era localizado en el Hito Tres Fronteras, a pocos metros del hotel de propiedad del gobernador. Una nota de un diario nacional crítico al kirchnerismo (al gobernador provincial de entonces se lo consideraba alineado políticamente al gobierno de la presidenta Cristina Fernández de Kirchner) cuestionaba su construcción en una de las provincias, como Misiones, con los peores indicadores de todo el pais. ${ }^{14}$

Pese a la gran inversión en la promoción del turismo, no bajaba desde Nación dinero directamente para obras, según denunciaba un concejal de la oposición quien además ponía en palabras un entendimiento que era frecuente encontrar en los pobladores: que era injusto que brille Cataratas y que en Puerto Iguazú estemos con tantas necesidades. El concejal entendía que ellos debían trabajar para que bajen en forma consensuada con acuerdos, con Parques Nacionales, con la Nación, para que efectivamente se distribuya un poquito más para Iguazú, indicando el reparto inequitativo de los recursos generados por las Cataratas y al escaso 3,5\% que recibía la ciudad ${ }^{15}$ - destinado a la promoción turística. Un diputado provincial, dirigente opositor, declaraba en un medio ese mismo año que Misiones destinaba mucho dinero para promocionar las Cataratas que luego no volvia para llevar a cabo politicas que beneficiaran a sus ciudadanos, y que el gobernador se beneficiaba con esto además del alto porcentaje - 62,5\% - que recibía la concesionaria a cargo del paseo: la empresa familiar de los Closs [familia del gobernador] Petrovalle - forma parte de la UTE [Unión Transitoria de Empresas, concesionaria de Cataratas] (...) el gobernador destina fortunas en promoción turistica para las Cataratas y es el principal beneficiado a través de su empresa familiar. ${ }^{16}$

14 "El faro de Closs que altera a Puerto Iguazú", por Gustavo Ybarra, La Nación, 12 de noviembre de 2012. Aunque una inversión diferente e inferior a la ideada inicialmente, esta obra inaugurada en setiembre de 2015 era estimada en 47 millones de pesos (aproximadamente cinco millones de dólares), y descripta en las crónicas como un show de luces, sonido y agua que consistía en un moderno sistema de aguas danzantes y cinco buscacielos que al activarse por la noche forman un faro virtual.

15 Las Cataratas significaban para Iguazú el 3,5\% de los 7\% que recibía la provincia; 27,5\% se destinaban a la administración de los parques nacionales y el 62,5\% a la empresa concesionaria. En esta distribución la empresa concesionaria recibía 30 millones de pesos de las entradas a las Cataratas, mientras que Iguazú solamente 2 millones. Con el nuevo intendente, que asume en diciembre de 2015, se implementa la tasa ecoturística municipal a partir de febrero de 2016 con la finalidad de financiar los servicios municipales que debe restar la Municipalidad, asi como el equipamiento vial y otras inversiones que resultan imprescindibles en el área de servicios públicos; justificaban esta medida en el gasto público municipal que los turistas generan durante su estancia en hoteles, pensiones y campings. www.lavozdeCataratas, 22 de enero de 2016.

16 "Vinculan al gobernador con concesionaria de Cataratas", www.diariopopular.com.ar, 6 de enero de 2013. 
Los dirigentes políticos eran localizados a través de un fondo común de conocimiento que comprendía sus reputaciones, y llamaba la atención que el Intendente mostraba un notorio crecimiento de su patrimonio personal, lo que era con frecuencia denunciado por dirigentes y medios opositores señalando la adquisición de nuevas propiedades, vehículos, una embarcación, hoteles y hostels, así como costosos viajes a destinos turísticos fuera del continente. Del mismo modo eran referidos eventos, congresos y conferencias realizados en los hoteles de las autoridades y subvencionados por el Estado. ${ }^{17}$

Aunque por una parte, se producía un acoplamiento conveniente entre las políticas públicas y los actores económicos del turismo y, además, un control y dominio de la actividad por las élites políticas provinciales que se veía reforzado por la intervención del gobierno central; por otra parte, era cuestionado un supuesto uso personalizado del 'espacio turístico' (Nogués Pedregal 2007) y de sus beneficios pecuniarios por las autoridades políticas (por su vez, empresarios de turismo), uso que impugnaba y deslegitimaba el alcance de tales políticas.

\section{Los barrios}

El crecimiento del turismo como política pública, además, producía tensiones con la expansión urbana y las necesidades de los barrios. Mientras que para estos dirigentes el turismo y los barrios comprendían dos focos de atención vinculados a votos, veremos que las acciones en los barrios eran limitadas, puesto que era extremamente restringido lo que el municipio podía realizar para mejorar sus condiciones.

En poco más de diez años la población había saltado de 32 mil habitantes, según el censo del 2000, a 60 o 70 mil habitantes de acuerdo a las estimaciones informales que hacían funcionarios de la municipalidad. Iguazú recuperaba la vitalidad perdida en los noventa - por entonces, ciudad fantasma - y se producía un abrumador incremento poblacional en poco tiempo. Este incremento revelaba una importante población llegada de otros lugares; el 80\% de la gente de Iguazú vino de afuera, me decía el presidente del Ente de Turismo Municipal, y realmente era posible observarlo en el cotidiano de la ciudad, donde 'el lugareño' mostraba una presencia minoritaria ante misioneros de diversas localidades, argentinos de distintas provincias, paraguayos y brasileños. Desde este organismo trabajaban mucho en la falta de sentido de pertenencia de la gente que vino, que siguen pensando en volverse, no logran identificarse con la ciudad. La gente no entiende que somos una ciudad de servicio [turistico] y reniega que hay largas filas (...) en la heladería, en la farmacia o en el restaurant (...) de que no hay dónde estacionar.

$\mathrm{El}$ ajuste que los pobladores experimentaban con el crecimiento del turismo, ${ }^{18} \mathrm{y}$ de los turistas invadiendo el centro de la ciudad como refiere la cita, era simultáneo a la abrupta expansión urbana que generaba graves problemas de sustentabilidad del municipio. Las iniciativas legislativas en 2007 hacían referencia a no poder dar cuenta y a cómo se traducía esa incapacidad en diferentes ámbitos de las

17 Primera Edición, "Gran Cuñado hace campaña por boliches", 22 de octubre de 2015; "La Esposa de Gran Cuñado recibió casi una hectárea para un negocio privado”, 28 de setiembre de 2015.

18 Es señalado en numerosos estudios que la relación entre residentes locales y turistas sería marcadamente asimétrica, dado que los primeros llevan el fardo del ajuste económico, social y cultural del turismo en sus ciudades (Salazar 2006: 106). 
dependencias de atención al público y reparticiones provinciales y nacionales con colas interminables y grandes pérdidas de tiempo. También se veían desbordadas empresas de servicios y bancos, y hasta las estaciones de carga de combustible (en las que participaban brasileros y paraguayos, por el conveniente precio más bajo de entonces).

Este problema ponía en jaque las mismas posibilidades de sustentar el turismo porque si no tenés cajero [bancario], agua, servicios, ¿cómo hacés para recibir más? (según razonaba una trabajadora de la municipalidad conversando conmigo). Iguazú necesita una estructura tres veces más grande de la que tiene declaraba en los medios un secretario municipal en 2015, y en la misma dirección me explicaba un funcionario sobre el problema del agua: la planta potabilizadora que se hizo para treinta mil habitantes hace dos años ya no es suficiente, no llega el agua a algunos lugares. El crecimiento del turismo de los últimos años había sido paralelo a la increíble expansión urbana y, con esta última, se multiplicaban las necesidades en dimensiones que permitían definirlas, además, como de grave problema social, según me decía un ex concejal y ex diputado opositor.

Se producía una expansión hacia el sur, el único lugar por donde Iguazú podía crecer demográficamente y el centro de la ciudad quedaba cada vez más alejado; en esa expansión habia barrios nuevos desde el último censo que no figuraban en ningún lado, según me decía un secretario municipal. Esos barrios no contaban con una mínima urbanización ni con servicios básicos, y su población no constituía contribuyentes impositivos porque se trataba de ocupantes de tierras fiscales. El presidente del Consejo Deliberante me explicaba que el $70 \%$ de Iguazú estaba intrusado, y las crónicas de los medios referían que la ocupación ilegal de tierras se había vuelto moneda corriente desde 2002. ${ }^{19}$

Se producían ocupaciones por familias pobres, empresarios, pequeños ganaderos y trabajadores rurales, sobre todo en tierras donadas por el Ejército Argentino al Municipio conocidas como las dos mil hectáreas, que alimentaban un importante mercado inmobiliario informal por el que una gran cantidad de pobladores locales - hasta funcionarios y el mismo intendente municipal, según sus propias declaraciones - contaban con terrenos, casas y chacras (y todos ellos se veían involucrados en constantes disputas sobre la extensión, los límites y la superposición de terrenos, por la ocupación de espacios verdes o calles, o por haber sido embaucados por ventas fraudulentas). Las iniciativas para reglamentar y regularizar las ocupaciones habían fracasado, como el plebiscito para reformar dos artículos de la Carta Orgánica Municipal en 2013, y era tenido como un problema que involucraba a toda la población. En torno de éste los iguazuences debatían sobre el merecimiento a la tenencia con argumentos recurrentes que disputaban cierta legitimidad moral y que se podían resumir en locales versus outsiders y necesidad versus lucro: les faltaba merecimiento a los que habían venido de otros lugares desde 2002 y que no tenian ganado su lugar y a empresarios y políticos (incluido el intendente); y contaban con merecimiento las personas que habian pasado las mil y una en la comunidad, que se quedaron en los '90, los que tenían necesidad de un lugar para vivir y los que se hicieron desde abajo.

Muchos entendían que eran tres los problemas graves de Iguazú: los terrenos, el agua y la luz. Para los funcionarios y concejales del oficialismo en 2014, sus acciones políticas en los barrios aunque

19 Las crónicas y algunos relatos se referían a un uso político, con fines electorales, que habría propiciado sucesivas ocupaciones ilegales. Sobre una caracterización de estas tierras fiscales en el proceso de ordenamiento territorial provincial, ver Nuñez (2009). 
eran claras y muy concretas: llevar luz, agua y abrir calles, alcanzaban a atender un mínimo de la demanda. No obstante, entendían que solucionando el problema central, la posesión efectiva, se podía resolver el mensurado y trazado de calles, para luego proceder a la provisión de los servicios básicos, el empedrado y el cordón cuneta.

La gran cantidad de población de los barrios nuevos (algunos de hasta dos mil habitantes) no pagaba impuestos municipales por no ser propietarios de los terrenos. Sumado a esta falta de pago, los habitantes de barrios creados en los '80 no querían pagar, porque nunca pagaron, según me explicaban algunos dirigentes políticos. Dada esta situación, un funcionario municipal refería que el municipio tenía inscriptos sólo cuatro mil contribuyentes y de éstos dos mil quinientos eran los aportantes efectivos.

Por otra parte, aquellos pobladores que vivían en barrios con terrenos regularizados y que eran contribuyentes, tampoco contaban con red de cloacas, saneamiento, cordón cuneta ni pavimento, y sus demandas mayormente no eran atendidas o sólo de forma aislada.

La incapacidad del gobierno municipal para resolver las carencias de infraestructura urbana que arrastraba la ciudad de décadas anteriores se sumaba a la imposibilidad de asumir la excesiva expansión urbana de los últimos años. Esta ineficacia era traducida por los pobladores en un registro de descrédito de la política y de los políticos y de injusticia, en crítica a las políticas públicas nacionales, provinciales y municipales centradas exclusivamente en el crecimiento del turismo (todo para el de afuera o siempre prioridad al de afuera). Dado que muchos dependían de esta actividad económica, esta disconformidad no se dirigía hacia el fenómeno en sí, ${ }^{20}$ sino hacia la postergación que producían esas políticas dadas las acuciantes condiciones de los barrios.

Para resumir este apartado, vimos entonces que para el intendente y los concejales oficialistas la política tenía como objetos los barrios y el turismo. En los primeros se expresaba en iniciativas que no conseguían generar soluciones definitivas a los problemas considerados graves y en un desfasaje negativo indudable entre la escasa capacidad institucional y las innumerables necesidades. En el segundo, como un universo de empresarios, inversores, hoteles, atractivos turísticos, turistas y eventos articulados en una forma particular de concebir la ciudad en tanto 'espacio turístico' y de actuar en ésta, y en una imbricación entre modelo de desarrollo de la actividad - articulado desde los niveles provinciales y nacionales - y la estructura política. No obstante, el turismo parecía expresarse como una arena de disputas y de tensiones sobre las políticas públicas, la distribución de los beneficios pecuniarios y el poder de definir y delinear formas de desarrollo local (Pinto, R. y X. Pereira, 2010). Parte de esas confrontaciones realizadas desde una posición de exclusión (eran escasas las instancias de participación), intentaban hacer valer una capacidad de acción estructurante de la población local.

20 Nogués Pedregal (2011) destaca que son pocas las sociedades que cuestionan la presencia de los turistas en general y la necesidad del turismo como estrategia para el desarrollo económico de los territorios. 


\section{Foz do Iguaçu y el problema del desarrollo}

En 2014 Foz se consolidaba como un destino importante del turismo de negocios - turismo que representaba el $45 \%$ del total de visitantes y cuyo movimiento financiero comprendía tres veces más que el de placer, según las declaraciones que hacían los representantes del área - , y como la tercera ciudad brasileña más visitada por extranjeros para eventos, atrás solamente de Rio de Janeiro y de São Paulo de acuerdo a la investigación realizada por la Fundación Getulio Vargas (en 2012 era la séptima). Este logro era adjudicado a la mejoría de la imagen de la ciudad y región, según explicaba en una entrevista de la prensa el presidente del organismo de promoción turística vinculado a Itaipú Binacional y al municipio, Fundo Iguaçu. La ciudad pasaba a ser conocida por sus virtudes y no más por sus defectos (y su imagen como frontera del contrabando y del crimen organizado), gracias a acciones positivas en los medios, marketing promocional, patrocinios y la definición de un calendario de eventos fijos, que atraían un nuevo perfil de turistas. ${ }^{21}$ En este fortalecimiento del turismo reflejado en el aumento de veintisiete mil camas a treinta mil en ese año, como una de las mejores infraestructuras para encuentros y reuniones, y vía politicas de gestión integrada - entre instituciones privadas y públicas - , la participación de Itaipú Binacional había sido decisiva. ${ }^{22}$

Al leer las noticias del importante diario local $A$ Gazeta de Foz do Iguaçu, me llamaba la atención la publicación regular de noticias referidas a este éxito del turismo de negocios. Hacia el segundo mes asistí a la II Conferencia Municipal del Turismo, evento que tenía como objetivo incorporar a la sociedad de forma democrática al proceso de discusión de políticas públicas destinadas al turismo, donde esperaba encontrar una asistencia masiva y la presencia de figuras del empresariado de la actividad turística y dirigentes locales. Sin embargo, me deparé con aproximadamente doscientas personas, promotores, trabajadores y estudiantes ligados a la actividad, con una presencia mínima de dirigentes locales y nula de grandes empresarios. ${ }^{23}$ No obstante, lo más llamativo fue que la Conferencia Municipal de Salud, realizada simultáneamente, congregaba mil doscientas personas con la asistencia masiva de representantes de entidades, vereadores y funcionarios en dos días de discusión y ocupando doce salas de trabajo; la de turismo insumía unas pocas horas y cuatro salas. En la oportunidad de una entrevista, un vereador me explicaba que a las personas les parecía que la Salud influia en la vida de ellos, que gran parte de la población no conseguía entender cuán importante era el turismo, y que los niños crecían sin saber qué era lo que incentivaba la economía.

Veremos a continuación los grandes temas de la sociedad iguaçuense según las perspectivas de los dirigentes locales. Éstos parecían expresarse muy nítidamente en los debates de sesión, en las audiencias públicas, en las Conferencias Municipales y como asuntos recurrentes en la prensa. A diferencia de Puerto Iguazú, me era posible encontrar profusas instancias institucionalizadas de debate - con sus

21 Y se refería a cuatro campañas de promoción turística llevadas adelante: Foz do Iguaçu destino del mundo, Temporada boa en Foz, Vote Cataratas y Foz do Iguaçu-Bem-vindo ao inesquecivel (A Gazeta, 22 de octubre de 2014).

22 “Gestão integrada, a protagonista de recordes do turismo de Foz", por Adilson Borges, A Gazeta, 8 de enero de 2016

23 Siguiendo las crónicas y referencias de los vereadores en los debates, el Conselho de Desenvolvimento Econômico e Social de Foz do Iguaçu (CODEFOZ) y el Sindicato de Hoteles, Restaurantes y bares (Sindhoteis), parecían las entidades que canalizaban sus demandas y preocupaciones. 
respectivos registros documentales -, y observar y reconocer aquellas polémicas de mayor centralidad. Además de los abundantes y extensos debates de Sesiones, muchos de ellos en el propio sitio digital de la Cámara Municipal, ${ }^{24}$ podía recurrir a las ediciones de la prensa local, que proporcionaban entrevistas a dirigentes locales, crónicas y notas de análisis político.

\section{La falta de integración del turismo}

Aunque esta actividad respondía por el 52\% del desarrollo económico y social de la ciudad en 2014, según indicaba una vereadora, era señalado también que alcanzaba sólo al diez por ciento de los trabajadores. ${ }^{25}$ La necesidad de fomentarlo no solo se confrontaba con la mínima cantidad de trabajadores que este sector económico absorbía sino también con preocupaciones dirigidas a repensar el turismo de negocios, que no distribuía renta en la ciudad, señalar la necesidad de turismo gratuito, rural, etc. y la falta de integración (el $40 \%$ de la población no conocía el Parque Nacional y las Cataratas, según los dichos de un vereador en sesión del 7 de marzo de 2007), o a denunciar algunas injusticias ${ }^{26}$ referidas a la concesión del Parque Nacional de las Cataratas. Asimismo, los recursos que invertía el Municipio para este sector eran bastante inferiores comparados con los 176 millones de reales ${ }^{27}$ - el 34\% de lo recaudado según el Secretario de Salud - que consumía la cartera municipal de Salud. Distintos vereadores referían tanto en 2007 como en 2014 que se trataba del área menos valorizada y de menores recursos al que, destacaba un vereador, se destinaban solo 5 millones de reales (en sesión del 24 de abril de 2014); esta baja inversión, según el rumor que difundía un medio de prensa, habría provocado la salida del Secretario de Turismo en diciembre de 2014.

Aunque consumiendo una parte importante del presupuesto del Municipio, lo destinado a Salud resultaba insuficiente, y la preocupación por estos gastos era también de los vereadores en 2007. En noviembre de 2014 el Secretario de Salud declaraba que existía un déficit de setenta y cuatro millones de reales. Aunque algunos vereadores entendían que el Hospital Municipal funcionaba como hospital regional (en 2012 se registraban setecientos sesenta y dos mil atenciones en el sistema de salud, para una población de doscientos cincuenta y seis mil personas ${ }^{28}$ ), sin recibir los recursos proporcionales con aportes estatales cada vez más escasos, para un vereador opositor se trataba de que la salud está cada vez peor por responsabilidad de las políticas del prefeito y por un uso irregular y corrupto de las recursos en esa área (sus insistentes y fundamentadas denuncias se vieron posteriormente confirmadas).

24 www.cmfi.pr.gov.br

25 Sesión ordinaria, 18 de marzo de 2014. En 2007 un vereador señalaba que el sector comprendía seis o siete mil trabajadores y cuarenta empresarios (sesión ordinaria del 13 de diciembre de 2007).

26 Mencionaban la recaudación en el parque, siendo superior a los R \$ 10 millones de los cuales sólo R \$ 3 millones quedaban en Foz; las concesiones del Parque Nacional y la licitación del Hotel das Cataratas sin tener en cuenta los intereses de las poblaciones existentes y sin una parcela para Foz en esta última (A Gazeta, “Boca Maldita”, 1 de diciembre de 2014).

27 Le seguía Educación, con 147 millones (“Orçamento de R\$ 720 mi para 2015 começa a ser votado hoje”, por Elson Marques, A Gazeta, 15 de diciembre de 2014).

28 “Orçamento de R \$ 720 mi para 2015 começa a ser votado hoje” por Elson Marques, A Gazeta, 15 de diciembre de 2015. 
Señalaban además de que el 60\% de la población vivía de la informalidad en 2014 y que era una de las ciudades del oeste paranaense con más beneficiarios de la asistencia federal en ayuda financiera para familias pobres del Programa Bolsa Familia, la tercera de mayor número de los municipios de Paraná en 2015. ${ }^{29}$ En esta informalidad debía considerarse la importancia del comercio de Ciudad del Este del que dependían trabajadores y empresarios residentes en Foz, así como comerciantes y hoteleros; incluso en 2014 los visitantes recibidos por las Cataratas y la posibilidad de hacer compras en la ciudad vecina se estimaba en cinco millones de personas anuales. Entre otras, la experiencia de 2007 había mostrado una fuerte caída de ventas en ese comercio que generaba el despido abrupto de muchos trabajadores brasileños que, al perder sus fuentes de ingreso, mudaban su perfil hacia el contrabando de productos ilícitos produciéndose un aumento alarmante de la violencia en la ciudad. ${ }^{30}$ En 2014 y 2015 la amenaza de la reducción de la cuota de compras (y de una crisis del comercio en Ciudad del Este), movilizaba a autoridades locales y federales brasileñas para lograr su mantenimiento.

Las propuestas de campaña de candidatos a legisladores estaduales que disputaban para las elecciones de octubre de 2014 comprendían, entre otros temas, los recursos a pleitear para Salud en el nivel estadual, mientras que las de candidatos a representantes federales incorporaban la lucha por mejorar la infraestructura de la ciudad y por la concreción de ciertas obras en tanto necesidades imponderables para el desarrollo, como el Porto Seco, el Segundo Puente, la Perimetral Este y la duplicación de la Rodovia de las Cataratas, entre otras. Al leer las actas de sesiones de los debates de la Cámara Municipal de 2007 me encontré con las mismas preocupaciones: la Salud, las obras de infraestructura y la logística de la ciudad, así como la referencia al bajo presupuesto destinado al Turismo por entonces.

\section{El Desarrollo y las Obras}

Aunque las posiciones de defensa o de denuncia de los vereadores podían divergir según las pertenencias partidarias, el estado de alianzas como base de apoyo o de oposición y las situaciones de disociación política - partidaria entre los tres niveles de gobierno, existían puntos de consenso sobre los cuales se expresaban con alguna frecuencia en idéntica dirección.

Coincidían en que debido a la posición geopolítica cualquier hecho que afectara a la ciudad tendría una repercusión mayor que en otras ciudades de Paraná. Su importancia en el escenario nacional estaba dada por ser una triple frontera y una de las ciudades con más instituciones y problemas federales del país; sin embargo, considerando su infraestructura y logística y las escasas políticas públicas federales y estaduales que atendían al municipio en sus demandas más sentidas, parecía ser cidade fim de

29 Atendía a 12.433 beneficiarios, según datos del Ministerio de Desenvolvimento Social e Combate à fome ("Programa Bolsa Família atendeu 12.433 beneficiários no município" por Tamara Soares, A Gazeta, 1 de febrero de 2016).

30 A partir del control estricto de la Receita y Policía Federal de la totalidad del tránsito en el Puente de la Amistad y alrededores, se producía una profunda crisis comercial en Ciudad del Este que originaba cierre de comercios, despidos de trabajadores brasileños y pérdida de ingresos de residencias, hoteles y comercios de Vila Portes y Jardim Jupira, afectando profundamente la economía de Foz. Se producía entonces una escalada de violencia que convertía a la ciudad en una de las de mayor índice de violencia del país (ver actas de sesiones del 5 de marzo, 10 de setiembre y 1 de octubre de 2007). Cardin (2009) destaca los problemas locales expandiéndose en toda la región por el desarrollo desigual de los municipios que la componen: '(...) los problemas existentes se expanden rápidamente y de forma descontrolada; basta observar los problemas referentes a la salud pública y al mercado de trabajo. Estos, aunque localizados, implican consecuencias simultáneas en las demás regiones y desencadenan el efecto dominó' (idem 166). 
linha. Mencionaban con frecuencia que no había evolucionado como las otras: que era la que menos había crecido entre las grandes de Paraná; que parecía estar fora do mapa; que en otras ciudades del Estado existía una logística que no se veía en Foz y que, incluso, ciudades menores poseían viaductos, trincheras e iluminación en la ruta. Del mismo modo en Salud, con frecuencia era mencionado que necesitaba un tratamiento diferenciado y mayores recursos, por el número de brasiguayos, ${ }^{31}$ el número de paraguayos, el número de vecinos y de municipios vecinos que diariamente usaban el sistema de salud (de más de ocho localidades de la región).

Entendían que era imprescindible contar con sus propios diputados para luchar por sus reclamos. De los representantes estaduales y federales se esperaba que buscaran soluciones a las demandas de la ciudad, que combatieran decisiones injustas y de omisión y que contribuyeran a la formulación de políticas públicas, la concreción de obras y la búsqueda de recursos.

Para ellos, los recursos se destinaban al municipio mediante proyectos y, por esto, parte de las actividades consistían en idear, discutir y definir proyectos, ser asistidos técnicamente en su elaboración, ir tras el organismo de financiamiento, cadastrar la propuesta, presentar toda la documentación exigida siguiendo los parámetros legales, acompañar el proceso de revisión y aprobación, y gestionar la liberación del recurso. Para los vereadores la falta de representantes de la ciudad significaba quedar sin fuerzas para sacar del papel proyectos fundamentales, como viaductos en la BR, la duplicación de la Rodovia de las Cataratas, la construcción de la Perimetral Este, el Proyecto Beira-Foz y el segundo puente (sesión del 5 de octubre de 2007). En octubre de 2014 un vereador que no alcanzaba los votos para ser electo diputado federal, afirmaba en un medio gráfico que, de no atenderse esos proyectos y obras de infraestructura, Foz do Iguaçu estará fadada a virar um barrio de Cascavel - localidad vecina, polo del agronegocio en el Estado de Paraná, con mayor fuerza política, considerada ciudad rival y, por su característica 'rural', distante de la moderna elegancia citadina de Foz.

Esta falta de representantes federales se debía a que los electores de Foz votaban a candidatos foráneos, de otras localidades estaduales, para representar el Estado de Paraná en el Congresso Nacional. Por tratarse de personas que mantenían lealtades con sus ciudades de origen, según acusaba un vereador, llegó a haber más de 60\% de votos de la ciudad para candidatos de fuera, porque las personas que se ocuparon con la construcción de la Itaipú tenian su raiz en sus lugares de origen (en sesión del 14 de noviembre de 2007). En 2014, aunque había disminuido ese porcentaje, aún el 23\% de los electores votaban para otros candidatos; incluso ${ }^{32}$, algunos de ellos que nunca habían visitado Foz conseguían dos mil votos (sesión del 16 de octubre de 2014). Por otra parte, también afectaba la representación de la ciudad el perfil de esos candidatos. Según destacaba un vereador en una entrevista que le hago, diez de los treinta diputados de Paraná eran vinculados al agronegocio en 2010.

Asimismo, la situación de alianzas y oposiciones entre partidos a nivel federal y estadual - que incidía en el nivel local - podía afectar el flujo de recursos y de obras para la ciudad. En 2014 la diso-

31 Albuquerque (2009) señala que genéricamente la categoría brasiguayos se refiere a brasileños que viven en Paraguay y que pertenecen a distintas clases sociales y trabajan en varios sectores de la economía. No obstante, indica que existe una variación de significados tratándose más bien de una identidad ambigua y negociada.

32 Gazeta, 8 de octubre de 2014. 
nancia política - partidaria del gobernador y el prefeito (ambos afines políticamente) con la presidenta Dilma Rousseff era vista como negativa, obligando a sumar más esfuerzos.

No solo el prefeito, los mismos vereadores llevaban adelante iniciativas para defender la ciudad, viajaban a discutir en Brasília (como cuando se debatía en el Congreso la Ley del sacoleiro en 2007), demandaban a la bancada paranaense intervenciones de apoyo, enmiendas y gestiones y hablaban con las autoridades políticas de su mismo signo partidario o con quienes tuvieran canal abierto, amistad o contacto. Articulaban relaciones partidarias, políticas y de amistad con parlamentarios y funcionarios de otros niveles de actuación, y esto muchas veces suponía intercambios de recursos por apoyo y votos en los momentos electorales; incluso, el presidente de Itaipú Binacional, por su extracción partidaria afín al gobierno central era tenido como pieza clave y fundamental en la búsqueda de recursos y gestión de proyectos para el municipio.

Las autoridades locales coincidían en la falta de inversión en infraestructura, y determinadas obras eran consideradas necesarias para el desarrollo. Creado en 2012 por la prefeitura, el Conselho de Desenvolvimento Econômico e Social de Foz do Iguaçu (Codefoz) unía organizaciones públicas y privadas en torno de proyectos e ideas para el desarrollo sustentable de la ciudad y su entorno, y defendía alcanzar la concreción de ciertas obras, entre otras las ya referidas (el segundo puente, la Perimetral Leste, la duplicación de la rodovía de las Cataratas y el Proyecto Beira-Foz, sumado al Puerto Seco). El turismo y la logística eran dos fuerzas económicas del municipio que, además, disputaban el mismo espacio físico: en tanto que para el turismo era imprescindible mostrar una ciudad atrayente, para la logística el tránsito pesado por la ciudad era inevitable hasta tanto no se construyera la Perimetral Este.

En 2014 la Cámara Municipal realizaba Audiencias Públicas destinadas a discutir la localización y características del Puerto Seco y la Perimetral Este. Del mismo modo, a fines de ese año se llevaba a cabo una Audiencia Pública sobre Desarrollo donde vereadores y representantes de entidades discutían las trabas para el desarrollo de la ciudad. Si bien algunas intervenciones de vereadores se referían a las necesidades de la población y los barrios marginales, la idea más resaltada, luego retomada por un cronista y un vereador en el diario $A$ Gazeta, señalaba que las obras de infraestructura resultaban fundamentales, y que la planificación estratégica y urbanistica era un medio para garantizarlas.

Para resumir este apartado, me interesa destacar que 'hacer política' para las autoridades locales suponía debatir (y hacerlo con la población), acordar resoluciones a problemas, definir proyectos y realizar gestiones en los otros niveles de actuación política buscando su aprobación, recursos y la concreción de obras de infraestructura entendidas como un medio para el desarrollo de la ciudad. La falta de participación de las autoridades locales en las definiciones, decisiones y políticas del gobierno central y en su tejido institucional conducía a diferentes esfuerzos que iban desde la generación de candidaturas para la representación federal, la coordinación de vínculos y relaciones para esa intermediación, hasta viajes y gestiones realizadas por los mismos vereadores. 


\section{Ciudad del Este y 'estar en crisis'}

Inicialmente buscaba indagar sobre las preocupaciones de los dirigentes locales de Ciudad del Este a través de los diarios de sesiones de la Junta Municipal, tal como hacía en Puerto Iguazú y en Foz do Iguaçu. Sin embargo, el Secretario Legislativo me negaba el acceso a las actas de sesión al decirme que estaba probibido $;^{33}$ pude confirmar que esta restricción extrema sobre el acceso a información afectaba también a los trabajadores de la prensa y a sectores de la población (el acceso a la información formaba parte de una demanda que hacían organizaciones sociales ${ }^{34}$ ) y, de este modo, pude entender que el escrutinio externo es interpretado como un gesto conspirativo y obedeciendo a la dinámica de disputa político - partidaria. Es decir, entendido como un uso para la denuncia y desacreditación con fines electorales.

El control sobre lo que se publicitaba podía observarse en distintas oportunidades. Al finalizar las sesiones, aquellas que pude acompañar en 2014 y 2015, los concejales se escabullían para evitar a periodistas y a quienes buscábamos entrevistas. En situaciones excepcionales concedían breves reportajes, sin embargo, éstos eran restringidos a medios, periodistas y ocasiones particulares. ${ }^{35}$ Según estos trabajadores, los concejales los acusaban de poner otra cosa y tergiversar todo, esto es, de participar de la disputa política.

Posteriormente fui entendiendo que las sesiones de la Junta Municipal en ese entonces no constituían por sí mismas un espacio de discusión sobre las preocupaciones de la ciudad. Cuando explicaba mi interés por saber cuáles eran para ellos los problemas de Ciudad del Este el presidente me respondía: Aqui no hay discusión técnica, casi no hay discusión y lo poco que hay no es sobre esas cuestiones, porque no saben. No obstante, pude observar que las diferencias en el ejercicio del oficio no parecían fundarse en distancias basadas en la performance intelectual y discursiva sino en singularidades de la propia 'política paraguaya.' Pese a las escasas y breves intervenciones en sesiones de corta duración, ${ }^{36}$ la dinámica generada a partir de la imposición de resoluciones tomadas a puertas cerradas de los concejales oficialistas sobre la minoría opositora, con constantes denuncias de ésta última por falta de transparencia, corrupción, etc., hacía que las interacciones tuvieran un fuerte tono de confrontación política - partidaria que se sobreponía fácilmente a otros registros. Que los concejales centraran muchos de sus esfuerzos en esta dinámica daba cuenta, a mi modo de ver, de cómo se trasladaba a los espacios de gobierno los vín-

33 Posteriormente el presidente de la Junta Municipal rectificaba esa respuesta y me exigía la presentación de un pedido formal, del que nunca recibiría respuesta institucional. Aunque sin proveer los diarios de sesión, se solidarizaba con mi causa facilitándome el acceso a algunos de los discursos de la intendenta de 2013 y 2014.

34 A fines del mes de mayo de 2014 organizaciones sociales se movilizaban exigiendo acceso a la información y que la municipalidad transparentara su gestión y que permitiera acceder a las rendiciones de cuentas ("Bochornosas actitudes de Sandra Zacarías", www.vanguardia.com.py, 24 de mayo de 2014; "Ciudad del Este marcha por acceso a la información”, www.hoy.com.py, 29 de mayo de 2014). En septiembre de 2014 el Congreso Nacional de Paraguay promulgaba la ley 5282/14 "De libre acceso ciudadano a la información pública y transparencia gubernamental" que obliga a instituciones estatales y funcionarios a divulgar información solicitada por los ciudadanos. La reglamentación de dicha ley es reciente, de septiembre de 2015, teniendo como antecedente el histórico fallo de la Corte Suprema que declaraba que los sueldos de los funcionarios son información pública.

35 Esta escasa colaboración y poco interés también son mencionados por Giménez Béliveau (2006).

36 En las sesiones que observé la duración variaba de veinte a cincuenta minutos, y la lectura de las actas de sesiones anteriores generalmente consumía una parte sustancial de las mismas. En la nueva conformación de la Junta con una mayoría opositora desde diciembre de 2015, las sesiones pasaron a tener una duración que podía superar las cinco horas. 
culos y conflictos inter e intra - partidarios y, sobre todo, que la vida político-partidaria se presentaba dominando las dimensiones de 'la política institucional'.

Para ilustrar mejor, muchas de estas prácticas mostraban una marcada continuidad y sobreposición de procesos administrativos y procesos políticos. Aunque muchos concejales llevaban meses sin cobrar sus salarios esto era aún mucho más pronunciado en el caso de los de la oposición (con atrasos de hasta un año), por eso mismo, interpretado en el marco de represalias y confrontaciones políticas. Dada la importancia de las demostraciones públicas de lealtad y simpatías políticas, el universo de la ciudad entera parecía ser pensado a través de una forma simple de clasificar a las personas entre amigos y enemigos ${ }^{37}$ según la alineación política. De hecho, el acceso a la información como también a recursos, cargos y toda la diversidad de bienes de los organismos gubernamentales era mediada $-\mathrm{y}$ posibilitada - por una ostensiva adscripción política al zacariísmo (por el líder Javier Zacarías Irún, ex intendente, líder del Partido Colorado y esposo de la actual intendenta). Del mismo modo, disponer de cargos, espacios y estructuras de los organismos gubernamentales (y en la misma Itaipú Binacional- Paraguay), era entendido como fuente de fuerza y de respaldo para la empresa política, tal como indicaba un cronista de un diario nacional al decir que Ciudad del Este era el bastión político de Javier Zacarías Irún y que, con su esposa como intendenta y su hermano como gobernador de Alto Paraná, se alzaba con el control politico de este Departamento. ${ }^{38}$ La fuerza política no solo se reflejaba en la cantidad de seguidores, ocupación de espacios gubernamentales, cargos y recursos sino además en el peso para imponer medidas, decisiones y políticas de gobierno.

Los medios de prensa, según me explicaba el dueño de un semanario local, llamaban la atención por su cantidad: cinco medios gráficos para una población de más de trescientos mil habitantes (Primera Plana, Vanguardia, La Jornada, Tn Press, AdnDigital). Todos podían ofrecer declaraciones que hacía la intendenta, entrevistas a concejales y autoridades de otros niveles, a comerciantes y a representantes de organizaciones y entidades; asimismo, resultaban una fuente de abundantes notas de análisis político y económico sobre aquellos asuntos que parecían objeto de acciones políticas locales. Estos medios, cuyas tiradas no superaban los 2500 ejemplares, eran caracterizados según su alineación política: $A d n$ digital al grupo Cartes [del presidente]; La Jornada a la municipalidad y hacia intereses económicos - politicos de Zacarias; TN Press recibia un poco de todos; Vanguardia como linea crítica u opositora al igual que el Semanario Primera Plana, éstos también como independientes cuyas fuentes de financiación se podían encontrar en el comercio. Sus notas eran casi en su totalidad anónimas, y pude constatar el interés en preservar el anonimato de los cronistas en una conversación con el dueño de un medio local.

Observando las publicaciones locales identificaba dos temas recurrentes: el comercio y la dinámica política - partidaria (alianzas internas, rivalidades, entre otras); sobre estos asuntos se publicaban noticias de tapa, páginas centrales, secciones especiales y editoriales. El comercio surgía como tema

37 Las crónicas mencionaban que el ex intendente, esposo de la actual intendente y líder partidario del Departamento Alto Paraná, solía repetir Para los amigos todo, para los enemigos la ley, parafraseando al Gral. Alfredo Stroessner (ver "Zacarías parafrasea al Gral. Alfredo Stroessner" en abc Color, m.abc.com.py, 24 de mayo de 2014). Esta frase, de autoría difícil de adjudicar, habría sido atribuida a distintos líderes europeos del siglo XX, incluso hasta a Perón en Argentina. Al respecto de esta forma simple de clasificar a las personas, Bailey (1998) ya nos llamó la atención sobre 'una regla no escrita de la política' que divide a los individuos con los que se relacionan en la arena política en amigos o enemigos.

38 Ver "Clan Zacarías tendría en sus manos el control político del Alto Paraná”, www.abc.com.py, 22 de julio de 2013. 
recurrente, sobre todo de las publicaciones consideradas independientes o criticas, en tanto actividad económica importante que sufría constantes crisis, comprometía a la ciudad y en la que los dirigentes locales son referidos participando de iniciativas políticas (con funcionarios de otros ámbitos de actuación), escuchando a comerciantes, empresarios, mesiteros y otros trabajadores y dando definiciones sobre su situación. Por su parte, los comerciantes discutían sobre este tema al igual que los cronistas, incluso desde medios de alcance nacional como el paraguayo ABC Color, el brasileño Folha de São Paulo y el argentino misionero El Territorio. Veremos que son ellos, son los comerciantes y cronistas quienes debaten sobre la ciudad, y sobre cómo ésta es pensada desde la crisis del comercio.

Siguiendo los discursos de la intendente durante los años 2013 y 2014, podía observar la centralidad de las obras públicas en tanto propuestas del municipio para solucionar esta crisis que atendían a mejorar su funcionamiento y fisonomía a través de la infraestructura urbana y el ordenamiento de la ciudad.

\section{La ciudad pensada desde la crisis del comercio}

Aunque el comercio parecía vivir recurrentes crisis y recuperaciones, muchos especialistas consultados por la prensa gráfica coincidían en que debía cambiarse el modelo de triangulación económica - de reventa de productos asiáticos y americanos - de dependencia de Brasil, destinado a perecer no solamente por la inviabilidad de sostener la gran vulnerabilidad económica a cada movimiento del país vecino, sino también porque con la creación del Mercosur se había establecido que en 2019 cualquier producto extrazona tendría un arancel único de importación dentro del bloque, lo que acabaría con la competitividad de los productos del comercio de Ciudad del Este. ${ }^{39}$ Con frecuencia se referían los dirigentes locales, departamentales y nacionales a las iniciativas y políticas para una necesaria diversificación de la economía (a través de la industrialización, ${ }^{40}$ la promoción del turismo receptivo y la inversión de capitales), no obstante, se articulaban acciones basadas en la necesidad de salvar el comercio e incluso, de potenciarlo a través de su reconversión hacia el turismo y la industrialización. Esta defensa parecía comprender tanto una demanda legítima como una fuente de medidas y acciones de los dirigentes locales y del ámbito nacional.

Podían encontrarse titulares de crónicas locales o extranjeras en distintos momentos de los últimos quince años - como en 2002, 2005, 2007, 2013, 2014 y 2015 - que se referían a la crisis del comercio y que anunciaban de forma dramática el fin de Ciudad del Este o el funeral de la ciudad o se muere la ciudad cuando se sucedían caídas estrepitosas de ventas seguidas de despidos, cierre de comercios e in-

39 Con el ingreso de Paraguay al Mercosur este país había renunciado a la reexportación debido a que en el acuerdo los países miembros convergen en la aplicación de un mismo arancel para los productos de extrazona. Al ingresar al Mercosur, Paraguay y Uruguay, siendo países de menor desarrollo relativo, obtenían una excepción que les permitía establecer una lista de productos importados sin o con bajos aranceles por un período determinado de tiempo ("El mayor negocio del país acaba en el 2010", Semanario Primera Plana, 29 de marzo al 4 de abril de 2007). En 2019 acabarían esas excepciones ("En 2019, debe tener listo nuevo modelo para Ciudad del Este", www. adndigital.com,py, 8 de julio de 2015).

40 La maquila parecía una actividad en crecimiento, en diez años se habían instalado 89 empresas mayormente localizadas en el departamento de Alto Paraná y empleaban cerca de 9 mil personas destacándose los rubros de autopartes y confecciones textiles (ver "Crisis del comercio fronterizo: impacto de la economía brasileña y oportunidades industriales”, www.abc.com,py, 21 de junio de 2015). En Ciudad del Este, esta actividad absorbía tres mil personas. 
cluso, comerciantes que abandonaban la ciudad. Esta mirada señalaba la centralidad y responsabilidad del comercio motorizando el municipio, adjudicaba responsables conocidos de la crisis (la lucha contra el contrabando de la Receita Federal Brasilera, la reducción de la cuota de compras en una ocasión, así como la subida del valor del dólar en Brasil) y, en años recientes, contribuía a invisibilizar el desarrollo económico positivo que otras actividades experimentaban. ${ }^{41}$

En junio de 2015 el cronista de un semanario indicaba que la crisis se agiganta porque la caída de ventas desde octubre de 2014 causaba una espiral inflacionaria que gradualmente alcanzaba a todo el sector económico, repercutiendo en todas las esferas. La crónica se titulaba Al rescate de Ciudad del Este, ${ }^{42}$ refería que un $90 \%$ vive del sector comercial y que en esos últimos meses más de mil negocios habian cerrado sus puertas, dejando en la calle casi tres mil personas. Esta cifra de tres mil desempleados en esa mitad de año también era señalada en crónicas de otras publicaciones (brasileñas y argentinas) ${ }^{43}$ y, por entonces, las noticias indicaban acciones de autoridades políticas nacionales paraguayas y brasileras para conseguir que la cuota de compras permitida para ciudadanos de Brasil se mantuviera en US\$ 300 .

El diario local de noticias Vanguardia en su sitio digital ofrecía dentro de su menú una ventana denominada Crisis, en la que permitía la visualización de entrevistas (mayormente de 2013) y en las que dirigentes locales políticos, representantes de organizaciones, comerciantes y empresarios se expresaban sobre cómo superar la crisis del comercio de ese año. Éstas contenían definiciones que colocaban a la ciudad como problema del comercio y del turismo, por su fisonomía y funcionamiento precarios reflejados en el caos, el desorden y la suciedad, el tránsito lento, la falta de asfalto en calles y avenidas, las veredas y espacios públicos totalmente ocupados por vendedores, la falta de alcantarillado, los vertederos de basura improvisados, la invasión de veredas y la falta de salidas de emergencia.

Transformar la fisonomía del microcentro era una demanda de los empresarios del comercio y del turismo. El gerente del Hotel Executive consideraba que se debía recuperar los espacios públicos como veredas y calles que estaban usurpadas y ocasionaban un caos. Por su vez, el vicepresidente de la Cámara de Comercio se refería, entre otras cosas, a que se tenía que cuidar la ciudad, mantenerla limpia, no arrojar basura a la calle, tratar mejor a la gente y venderles productos buenos. En una entrevista en 2014 el Presidente de la Cámara de Importadores y Comerciantes del Alto Paraná señalaba del mismo modo que se debía arreglar la ciudad, limpiar y seguir trabajando en el ordenamiento como en tratar bien al turista y ofrecerles productos genuinos. Y en febrero de 2015 el relato de una crónica refería a una reunión con el presidente Cartes en la que el sector había solicitado mayor inversión pública en la capital departamental, para levantar los ánimos de los comerciantes y mejorar la imagen de la ciudad y que urgía el

41 Una cronista refería a que mientras en la zona comercial, concentrada en un poco más de diez cuadras en la zona del microcentro, sólo se habla de crisis, en las afueras se observan importantes y dinámicas inversiones en áreas de servicio e industrial ("Mientras que en el centro de Ciudad del Este se habla de crisis en las afueras se multiplican las inversiones", www.diarioprimeraplana.com, 15 de abril de 2015). Del mismo modo son mencionado el agronegocio, los servicios turísticos y gastronómicos ("Reconfiguración”, www.vanguardia.com.py, 21 de abril de 2015).

42 www.diarioprimeraplana.com, 17 de junio de 2015.

43 En una entrevista un comerciante de la Cámara de Comercio de Ciudad del Este señalaba que la cifra de despido en 2015 habría sido de cinco a diez mil trabajadores ("Comerciante habla de una perspectiva bastante oscura para Ciudad del Este", www.diariolajornada. com.py, 26 de enero de 2016). La dificultad para estimar con precisión la cantidad de despidos se vinculaba al importante carácter informal de su economía lo que incluía las contrataciones, y a que muchos brasileños eran trabajadores ilegales y, por esto, tampoco formalizados. 
ordenamiento, hermoseamiento y mejoras de la infraestructura del microcentro para volver a ser atractiva; y el cronista agregaba piden mayor voluntad de las autoridades y que los discursos politicos sean cumplidos.

Las autoridades locales, por su parte, defendían la fuerte inversión en el microcentro que hacía la intendencia. Según declaraciones del ex intendente en 2013, los esfuerzos se centraban en ordenar y mejorar estructuralmente, trabajar en seguridad, limpieza, iluminación y buena atención a turistas. Desde 2003 el municipio implementaba iniciativas dentro de un Plan que cambiaría su fisonomía y que buscaba recuperar espacios públicos, mejorar el tránsito, asfaltar calles y solucionar el problema de los mesiteros en la vía pública ${ }^{44}$. Tras décadas de comercialización de espacios públicos, según gustaba decir la intendente en sus discursos, con venta de patrimonio municipal y tierras virladas a sus propios dueños para construir shopping, ocupar zonas verdes e invadir veredas, entre otros, se buscaba que la ciudad recuperase los espacios públicos usurpados; descongestionar el tránsito de la zona céntrica; presentar una ciudad limpia y ordenada a los turistas y despejar calles y veredas.

El punto de partida, señalaba un analista económico de un semanario local en 2014, consistía en la solución del problema social de los mesiteros. Aunque se habían derribado y desalojado algunas áreas, las crónicas denunciaban que sólo unos pocos vendedores eran reubicados y la mayoría continuaba en espacios públicos; para los comerciantes las políticas del municipio estaban lejos de terminar con la venta callejera, que asociaban con los productos falsificados y de mala calidad, las estafas y los engaños a los compristas.

Desde 2003 a 2015 habían sido ejecutadas tres etapas del Plan de Reordenamiento del microcentro, consistentes en la demolición y retirada de ocupaciones irregulares y en la instalación de casillas y áreas de placer. El plan urbanístico para cambiar la fisonomía del caótico centro suponía una inversión de 50 millones de dólares. Además, se preveía la ampliación de arterias y pasarelas, estacionamientos subterráneos, construcción de sanitarios, plazas y anfiteatros.

En declaraciones de la intendenta, la gran inversión en obras del estado por el municipio y la gobernación debía entenderse como medidas para enfrentar la crisis del comercio. En sus discursos de 2013 y 2014 hacía referencias a múltiples obras, viales y de infraestructura e incluso a inversiones privadas en hoteles, estacionamiento, etc., expresando por entonces apostar al proyecto de hacer una ciudad turística y que los turistas quieran quedarse en la ciudad más tiempo, no solo a comprar sino a disfrutar. La ciudad había tenido un crecimiento vertiginoso, no planificado y tenía deficiencias múltiples además de la falta de diversos servicios básicos. El Plan Maestro de Desarrollo Urbanistico lanzado en marzo de 2014, con la presencia del propio presidente Cartes y el urbanista brasileño que lo elaboraba, buscaba transformarla en una ciudad moderna. ${ }^{45}$ La crónica de un semanario local criticaba que un año después esta propuesta no salía de los papeles y maquetas a pesar del pago ya realizado de un porcentaje importante del costo total de 490 mil dólares.

El presidente de la Junta me había advertido sobre la centralidad de las obras (Obras viales, casi todo va para ahí). En los medios gráficos y las declaraciones de la intendenta era señalado que la muni-

44 Para una mayor comprensión del significado de las formas de venta y ocupación del espacio de estos vendedores y su lugar en el mercado de la ciudad, ver Rabossi (2003).

45 Aunque no parece salir de una narrativa, la modernización que se plantea aquí tal como es posible observar en ciudades latinoamericanas durante el siglo XX, también significa ver la planificación urbana como un modo de 'salir del atraso'. 
cipalidad se había endeudado en 2014 por diez años para llevar adelante estos proyectos. La gran parte de las obras estaban siendo realizadas con presupuesto municipal y unas pocas por el gobierno departamental, con la novedad del aporte del gobierno nacional en viaductos y paso a nivel, la posibilidad de mejora del alcantarillado y el refuerzo de la electricidad en el centro después de dieciocho años de no recibir del gobierno nacional, según me explicaba un funcionario de la municipalidad.

\section{Entre la rivalidad y la alianza con el presidente}

Era posible observar entendimientos que enfatizaban la importancia de los vínculos entre el líder local y el nacional, ambos del mismo signo partidario, para interpretar el auxilio del segundo a los problemas de la ciudad. ${ }^{46}$ Las obras del gobierno nacional conseguidos en años recientes parecían formar parte de un flujo de intercambios entre el ex intendente y el presidente que, no obstante, variaba conforme el estado de alianzas, rivalidades y disputas entre ambos. El ex intendente, líder del partido del Departamento de Alto Paraná, había contribuido dando apoyo político y electoral de su línea política en las elecciones de 2013 para el triunfo del líder nacional. Posteriormente exhibía desentendimientos, rivalizaba por el control partidario y la definición de las próximas presidenciales y contaba con seguidores dentro del parlamento nacional y del partido cuyas decisiones de confrontación causaban la molestia del mandatario. Algunas referencias sugerían que esto era así porque el presidente no había cumplido con lo acordado; no obstante, la amenaza de intervención de la comuna por parlamentarios nacionales y referentes partidarios de segunda línea ${ }^{47}$ según algunas crónicas, lo llevaban a aliarse nuevamente unos meses después. La situación de los vínculos personalizados entre ambos comprometía a la ciudad y los líderes parecían un recurso principal para entender las políticas sobre el comercio.

El presidente Cartes al asumir, señalaban algunos relatos, les había prometido respuestas y planes para salvar el comercio, un plan verdadero que comprendiera inversiones, incentivos fiscales y fomentar el turismo; el ex intendente le había pedido antes de las elecciones hacer realidad el proyecto de un Duty Free en Ciudad del Este, transformando su sistema actual en una gran tienda libre de impuestos. Los representantes de las cámaras que congregaban a comerciantes e importadores del municipio y del Departamento Alto Paraná se expresaban reiteradamente a favor de la reducción del impuesto a la importación y el establecimiento de regímenes especiales, así como de la creación de zonas francas.

En 2009 podía haber sido la segunda ciudad más importante del Paraguay por su recaudación tributaria, atrás de Asunción; sin embargo según los registros de Aduanas en 2015 las recaudaciones del comercio constituían casi el $15 \%$ del total del país. ${ }^{48}$ De todos modos, seguía siendo un alto porcentaje que explicaba por qué el presidente no aprobaba la modificación de la carga tributaria y, al igual

46 Ver por ejemplo, "Línea cortada entre HC y Zacarías Irún impide plan contra la crisis", por Luis Alen, www.diarioprimeraplana.com, 14 de enero de 2015.

47 Por denuncias de uso irregular de fondos recibidos por los municipios de Fonacide (Fondo Nacional de Inversión Pública y Desarrollo), en concepto de compensación por la cesión de la energía de la Entidad Binacional Itaipú al Brasil, cuyo destino era la educación y la investigación científica, la inversión en infraestructura, la salud y el crédito.

48 Ver "Se estudia la forma de cómo mantener competitividad del comercio de Ciudad del Este", www.diarioprimeraplana.com, 29 de octubre de 2014. 
que la Dirección de Aduanas, rechazaba la instalación de un Duty Free en la ciudad. No obstante, algunos relatos señalaban que esto obedecía a un interés del mandatario por regular y disminuir la fuerza política del líder local.

Las autoridades locales y departamentales, por lo general, apoyaban y acompañaban las demandas de los comerciantes y articulaban apoyos del ámbito nacional. Puesto que era entendido que el proyecto político del ex intendente se entrelazaba con la situación y el futuro del comercio (cuya fuerza recaudatoria podía utilizar para reivindicar la fuerza política de su figura), y que los comerciantes representaban una importante base de apoyo electoral, eran frecuentes las iniciativas que atendieran a paliar la crisis. Aunque este régimen posteriormente no se aplicaba, orientando apoyos e influencias propias el ex intendente en 2014 conseguia la aprobación de la Corte Suprema al proyecto del Duty Free fuera de las instalaciones aduaneras. ${ }^{49}$

Era referido que el líder aspiraba a que Ciudad del Este fuera tratada como una ciudad comercial en el Mercosur, con un sistema diferenciado de tributación aduanera destinado a toda Sudamérica. Eso significaba negociar con Brasil una mayor apertura en el bloque regional en un momento bastante desfavorable, de fuerte control fiscal y militar de ese país del contrabando. Sin embargo, también era indicado en las crónicas que el presidente tenía una posición comprometida en el combate al contrabando de cigarrillos; la prensa brasileña, argentina y la paraguaya local de línea critica, lo acusaban de tener responsabilidad con su industria billonaria en un esquema de contrabando masivo de cigarrillos hacia casi todos los paises de Latinoamérica, y de ser investigado por la justicia brasileña por tráfico ilegal ${ }^{50}$. Esta situación hacía poco viable la negociación de la apertura deseada por el líder local.

Resumiendo, propuse que los comerciantes y cronistas eran quienes discutían sobre la ciudad y ésta era pensada desde la crisis del comercio. Aunque impugnados por su incompletitud o no realización e imbricados en proyectos políticos de crecimiento de los líderes, en los planes y obras de la intendencia y en los acuerdos e intercambios electorales (entre líderes y con bases electorales), la política buscaba erigirse como medio de transformar la ciudad en su fisonomía, funcionamiento y protagonismo para contribuir, de este modo, a salvar el comercio y producir la diversificación de su economía; y suponía, además, considerar otras dimensiones que escapaban al amplio margen de acción de los dos líderes, como la lucha contra el contrabando y las relaciones con el país vecino. Los espacios sociales de escala diferente se articulaban en función del estado de relaciones personalizadas entre líderes, y de sus fuerzas y pesos políticos para imponer medidas y decisiones con independencia de los ámbitos jurídicoadministrativos y atendiendo a las posiciones político - partidarias.

49 “Zacarías Irún usará Duty Free para liderar la oposición a Cartes”, por Luis Alen, www.diarioprimeraplana.com, 24 de setiembre de 2014. Esta aprobación habilitaba a una empresa propietaria de un shopping; no obstante, el Director de Industria y Comercio de la Gobernación de Alto Paraná posteriormente señalaba que este régimen no se aplicaría por las más de cinco mil tiendas que tenía la ciudad (“Régimen no se aplicará, dice autoridad de Gobernación”, www.abc.com.py, 15 de agosto de 2014).

50 "Brasil vuelve a la política del 'vecino pobre’ porque Cartes se lo permite”, por Luis Alen, www.diarioprimeraplana.com, 19 al 25 de mayo de 2015. Ver también "O patrão do tabaco" por Mauri König y Diego Antonelli, www.gazetadopovo.com.br, 22 de marzo de 2014; y "Cartes fabrica la mitad de cigarrillos del contrabando a la Argentina” por Facundo Barrio, www.perfil,com, 28 de abril de 2013. Según el Indesf (Instituto de Desenvolvimento Económico e Social de Fronteiras), el principal producto decomisado eran cigarrillos, que representaba el $67 \%$ de todas las incautaciones en 2014 y la mayoría fabricados por Tobesa, propiedad del presidente. La Receita, la Policía Federal y la Policía Ferroviaria en ese año habían incautado cigarrillos paraguayos por un valor de $\$ \mathrm{R} 4.700$ millones en impuestos evadidos al fisco brasileño ("Brasil busca 'blindar' frontera para frenar el contrabando desde Paraguay”, www.diarioprimeraplana.com, 19 al 25 de marzo de 2015). 


\section{Reflexiones Finales}

En Puerto Iguazú son tematizados la expansión urbana y el crecimiento del turismo como problemas, teniendo como punto de referencia la ciudad con escaso desarrollo turístico y profundamente empobrecida y reducida a partir del éxodo de sus pobladores en los años '90. Me parece que, por su vez, el desarrollo en Foz es pensado a partir del crecimiento económico alcanzado desde los años '80 con sus proyectos de modernidad: la represa de Itaipú, la apertura y fomento del comercio fronterizo con Paraguay y el apoyo al desarrollo del turismo (Catta 2012). Por su parte, la crisis del comercio tiene como horizonte la necesaria transformación de la economía y de las condiciones urbanas, y siendo que Ciudad del Este florece y su urbanización se expande caóticamente con el vertiginoso despegue de esa actividad, esta transformación parecía suponer la reinvención de la propia ciudad. El crecimiento y expansión, el desarrollo y la crisis pueden ser vistos como núcleos duros desde donde estas ciudades son tematizadas.

Buscando aproximarme a la política que es hecha, que dicen hacer, o la que las personas identifican como siendo hecha por los otros, describí cómo las autoridades locales, los pobladores, los cronistas y comerciantes discutían, denunciaban y disputaban sobre los temas o problemas considerados cardinales, y cómo los políticos 'hacían política' al respecto de éstos. Desplegados en agendas, objetos, relaciones, medidas y decisiones políticas, me detuve en peculiaridades que nos permiten marcar sus diferencias más que similitudes. Asímismo, propuse formas específicas en las que articulaban espacios sociales de escala diferente.

En Foz do Iguaçu vimos que la política se hacía debatiendo, en la participación y definición colectiva, proponiendo e ideando la ciudad deseada, y definiendo resoluciones y proyectos que buscaban gestionar en los otros niveles de actuación política. Dado que muchas decisiones y medidas dependían del gobierno central, además de recursos, la falta de representantes federales y la disociación político partidaria entre los gobiernos nacional y municipal eran tenidos como un límite a su participación y a la acción política local. De este modo, la articulación entre esos espacios se dirimía intensificando las intermediaciones y suponía un saber sobre organismos, canales burocráticos y proyectos.

En Puerto Iguazú pensar la ciudad como reducto económico permitía que el 'hacer política' fuera entendido, fundamentalmente, como contribuir al crecimiento del turismo. Vimos que las tensiones y contradicciones de esa centralidad se reflejaban en la cartografía de las dos ciudades y en la resistencia a las políticas públicas como políticas excluyentes y corruptas. La articulación de espacios sociales de escala diferente era realizada desde las autoridades provinciales, como nexo entre las autoridades locales y las nacionales, resaltando la escasa participación (incluso, de la misma población local) en la definición de las medidas delineadas desde los otros niveles.

En Ciudad del Este 'hacer política' se expresaba en llevar adelante disputas político-partidarias desde el propio tejido institucional - administrativo y buscaba legitimarse como un medio de transformar la ciudad en su fisonomía, funcionamiento y protagonismo, lo que para cronistas y comerciantes constituían promesas incumplidas y proyectos incompletos. La articulación de espacios de escala diferente se realizaba desde dos figuras y sus posiciones de líderes político - partidarios dominando 
estructuras de gobierno e imponiendo decisiones sobre la ciudad. Lo que estaba en juego en esta forma de 'hacer política' es el territorio político además de la estrategia (electoral), y suponía que los límites de éste y de la acción política eran móviles y dependían del estado de fuerzas políticas.

Del mismo modo, buscaba dar cuenta de las singularidades que la politica adquiere, vimos que en Puerto Iguazú ella aparecía en un horizonte restringido, imbricada a una actividad económica y asociada a prácticas de control y uso como espacio turístico; en Ciudad del Este se expresaba en la intersección entre proyectos políticos de crecimiento, el control de organismos gubernamentales y relaciones políticas personalizadas; mientras que en Foz do Iguaçu, ella parece entenderse como la discusión e implementación de políticas públicas participativas.

En este trabajo propuse evitar abordajes que entendieran el espacio de estas tres ciudades componiendo una unidad a priori así como conceptos que facilitaran observar similitudes, en detrimento de la diversidad como función de la proximidad (Lévi-Strauss 1999). Siguiendo las perspectivas de las personas de esos universos, vemos que aunque compartiendo temas o problemas translocales como el turismo de placer, el turismo de compras, el comercio fronterizo, etc.; estando involucradas en agendas e instituciones nacionales y transnacionales que alteran significativamente sus realidades locales; conteniendo una gran cantidad de población (migrante y flotante) sentida como excesiva en las limitadas capacidades de los municipios (en la regulación y ordenamiento del espacio urbano del microcentro, en la provisión del servicio de salud municipal y en la regularización de las tierras y la infraestructura urbana, entre los que referí), las particularidades de sentidos y prácticas de la política de los dirigentes locales de estas ciudades son, ante todo, disímiles y muestran fuertes singularidades en cada una de ellas.

Fernanda Maidana éposdoutoranda e professora colaboradora do IELA/UNILA (Foz do Iguaçu, Brasil), Doutora em Antropologia Social/Universidade de Brasilia (Brasil) e Mestre em Antropologial Universidade Federal Fluminense (Rio de Janeiro, Brasil).

\section{Referências bibliográficas}

ALBUQUERQUE, José Lindomar. 2008. "Fronteiras e identidades em movimento: Fluxos migratórios e disputas de poder na fronteira Paraguai- Brasil”. Cadernos CERU 19(1): 49- 63. .2009. "A dinâmica das fronteiras: deslocamento e circulação dos 'brasiguaios' entre os limites nacionais”. Horizontes Antropológicos 15(31): 137- 166.

BAILEY, Frederick G. 1998. The need for enemies: a bestiary of poltical forms. Ithaca: Cornell University Press.

BEZERRA, Marcos Otavio. 1999. Em nome das “bases". Política, favor e dependência pessoal. Rio de Janeiro: Relume-Dumará.

. 2006. "O "Caminho das Pedras": representação política e acesso ao governo federal segundo o ponto de vista de políticos municipais”. In: Palmeira, M. e Barreira, C. (orgs.) Politica no Brasil. 
Visões de antropólogos. RJ: NUAP/Relume - Dumará.

BOLTANSKI, Luc y Lauren Thévenot. 1991. De la justification: les économies de la grandeur. Paris: Galliard.

CARDIN, Eric Gustavo. 2009. "Globalizaçao e desenvolvimento regional na Tríplice Fronteira”. Revista Ciências Sociais Unisinos 45: 162 - 170.

CATTA, Luis Eduardo. 2012. "Impactos de la Modernidad: los Excluidos del progreso". Revista del CESLA 15: 89 - 228.

COMERFORD, John Cunha y Marcos Otávio Bezerra. 2013. "Etnografias da política: uma apresentação da Coleção Antropologia da Política”. Análise Social, 207, XLVIII (2): 465 - 489.

FREDERIC, Sabina y Germán Soprano. 2008. "Panorama temático: antropología y política en la Argentina”. Estudios de Antropología Social 1(1): 132 - 190.

FORTES, Meyer \& Evans-Pritchard, E.E. 2010 [1940]. “Introducción”. In: Sistemas Politicos Africanos. México: Centro de Investigaciones y Estudios Superiores en Antropología Social.

GIMÉNEZ BÉLIVEAU, Verónica. 2011. “La 'triple frontera' y sus representaciones. Políticos y funcionarios piensan la frontera”. Frontera Norte 23 (46): 7 - 34.

GRIMSON, Alejandro. 2005. "Fronteras, estados e identificaciones en el Cono Sur”. In: Mato, D. (comp.) Cultura, Politica y Sociedad. Perspectivas Latinoamericanas. Bs As.: Clacso.

LATOUR, Bruno. 2008. Reensamblar lo social. Una introducción a la teoría del actor - red. Bs. As.: Manantial.

LÉVI-STRAUSS, Claude. 1999. “Raza e Historia”. In:Raza y Cultura. Madrid: Alianza.

MONTENEGRO, Silvia y Giménez Béliveau, Verónica (dir.). 2010. La 'Triple Frontera'. Dinámicas culturales y procesos transnacionales. Buenos Aires: Espacio Editorial.

NOGUÉS PEDREGAL, Antonio Miguel. 2011. "Prólogo a la edición española: La antropología entre lo cultural y el turismo". In: Jeremy Boissevain (ed): Lidiar con turistas. Barcelona: Edicions.

.2007. "Lugares y territorios: la segregación social y política en contextos turísticos". In: LAGUNAS, D. (coord.) Antropología y turismo. Claves culturales y disciplinares. México: Plaza y Valdés.

NUÑEZ, Ana Carolina. 2009. "En Puerto Iguazú, Misiones (Arg.). Ordenamiento territorial y políticas hegemónicas. Una visión crítica”. XXVII Congreso de la Asociación Latinoamericana de sociología, Asociación Latinoamericana de Sociología, Buenos Aires.

PALMEIRA, M. e Barreira, C. 2006. “Introdução”. In: M. Palmeira e C Barreira (orgs.) Política no Brasil. Visões de antropólogos. RJ: NUAP/Relume - Dumará.

PINHEIRO - MACHADO, Rosana. 2011. Made in China: (in)formalidade, pirataria e redes sociais na rota China-Paraguai-Brasil. São Paulo: Hucitec

PINTO, Roque y Xerardo Pereiro. 2010. "Turismo e Antropologia: contribuições para um debate plural”. Revista Turimo \& Desenvolvimento 13.

RABOSSI, Fernando. 2003. En las calles de Ciudad del Este: Una etnografía del comercio de frontera. Asunción: Centro de Estudios Antropológicos de la Universidad Católica. 
RENOLDI, Brígida. 2013. "Fronteras que caminan: relaciones de movilidad en un límite trinacional”. Revista Trasporte y Territorio 9: 123 - 140.

SALAZAR, Noel B. 2006. "Antropología del Turismo en países en desarrollo: análisis crítico de las culturas, poderes e identidades generados por el turismo". Tabula Rasa 5: 99 - 128. Bogotá.

VENTURINI, Tomasso. 2010. "Diving in magma: how to explore controversies with actor network theory”. Public Understanding of Science 19: 258 - 273. 


\title{
Preocupaciones y desafíos de la política en tres ciudades de frontera: Puerto Igua- zú, Foz do Iguaçu y Ciudad del Este
}

Resumo: Na procura por identificar o que é preciso considerar para compreender a política que fazem os prefeitos e vereadores de Puerto Iguazú (Argentina), Foz do Iguaçu (Brasil) e Ciudad del Este (Paraguai), abordo as preocupações ou grandes temas sobre a cidade conforme são entendidos por dirigentes políticos, habitantes, cronistas e comerciantes. Em Puerto Iguazú, a expansão da cidade perante uma urbanização limitada, precária e excludente, em tensão com o crescimento do turismo; em Foz do Iguaçu, o desenvolvimento socioeconômico e os obstáculos para alcançá-lo, desde a falta de concreção de certas obras de infraestrutura para a logística e o turismo; em Ciudad del Este, a crise do comércio como forma de pensar e transformar a cidade. Proponho que os dirigentes políticos das três prefeituras relacionam espaços sociais de escalas diferentes sob formas diversas e que, mesmo compartilhando assuntos ou problemas translocais, os sentidos e as práticas da política são, antes de tudo, dessemelhantes e expressam fortes singularidades.

Palavras-chaves: Política em cidades de fronteira; Política na Tríplice Fronteira; Práticas e sentidos da política; Cidades de fronteira

\section{Concerns and challenges of politics in three border cities: Puerto Iguazú, Foz do Iguaçu y Ciudad del Este}

\begin{abstract}
Seeking to identify what we need to consider to understand the politics that the mayors and councillors of Puerto Iguazu (Argentina), Foz do Iguaçu (Brazil) and Ciudad del Este (Paraguay) make, I focus in the concerns or major issues about the city according to how they are understood by political leaders, residents, reporters and retailers. In Puerto Iguazu, the expansion of the city in front of a limited, precarious and exclusive urbanization in tension with the growth of tourism. In Foz do Iguaçu, the socio- economic development and the obstacles to achieve it as the lack of certain specific infrastructure for logistics and tourism, and in Ciudad del Este the trade crisis as a way to think and transform the city. I propose that the political leaders of the three municipalities relate social spaces of different scales in many ways and although sharing translocal issues or problems, senses and practices of politics are, above all, dissimilars and they express strong singularities.
\end{abstract}

Keywords: Politics in border cities; Politics in the Triple Border; practices and senses of politics; Cities of border

RECEBIDO: $20 / 04 / 2016$

APROVADO: $26 / 03 / 2017$ 